\title{
NILAI THEOLOGIS DALAM SERAT WEDHATAMA
}

\author{
oleh Purwadi \\ FBS Universitas Negeri Yogyakarta
}

\begin{abstract}
Serat Wedhatama is a Javanese literary work by Sri Mangkunegara IV. It contains considerable piwulang luhur (or valuable teachings) in the ethics of life in social interaction. This article concerns a research aiming at describing the theological values in Serat Wedhatama which are often referred to as Sembah Raga, Sembah Cipta, Sembah Jiwa, and Sembah Rasa. They are said to coincide with what are usually referred to in Moslem sufism as syariat, tarikat, hakikat, and makrifat as well as with what are always referred to in Hinduism as artha, kama, dharma, and muksa. In that work of his, Sri Mangkunegara IV is able to make a successful discourse of harmony among traditional Javanese principles, Islamic principles, and Hindu principles. Serat Wedhatama could thus become important reading for Javanese people.
\end{abstract}

Keywords : theology, Serat Wedhatama, ethics of life

\section{A. PENDAhuluan}

Inti pandangan dunia Jawa terletak pada anggapan bahwa di belakang gejala-gejala lahiriah terdapat kekuatan-kekuatan kosmis numinus sebagai realitas yang sebenarnya, dan realitas sebenarnya manusia adalah batinnya yang berakar dalam dunia numinus itu. Hidup manusia akan berhasil sejauh ia dapat menyesuaikan diri dengan realitas itu, atau sejauh ia dapat menembus sampai padanya. Kriterium keberhasilannya pada akhirnya adalah suatu keadaan psikologis, yaitu keadaan slamet, atau ketentraman batin yang tenang. Nampak pula bahwa keadaan itu hanya dapat tercapai apabila kita memiliki sikap batin yang tepat. Dengan pertanyaan tentang sikap batin yang tepat itu, tergambarkan ciri khas etika Jawa (Magnis Suseno 1993: 64)

Semboyan sebagai inti bersama usaha semua golongan kebatinan yakni: sêpi ing pamrih, rame ing gawe, memayu hayuning bawana, yang dapat diterjemahkan sebagai menjadi bebas dari kepentingan sendiri, melakukan kewajiban-kewajibannya, memperindah dunia (Subagyo, 1973: 82). Hal tersebut merupakan kategori tempat yang tepat sebagai titik acuan fundamental bagi pandangan-pandangan moral. Seseorang yang telah memiliki kematangan batin, tidak takut dan was-was lagi terhadap manunggalnya rohani pada keagungan Ilahi, yang ia resapkan sedalam-dalamnya dan ia jelmakan kembali dalam suasana sunyi sepi (Kamajaya, 1992: 123). Lalu ia simpan kembali dipusat terdalam dalam lubuk hati sanubari. Pada saat itu terbukalah tirai penutup antara dia dengan Tuhannya, sehingga dengan mata hatinya ia dapat melihat Tuhannya, sekejap, seolah-olah hanya dalam jarak waktu antara sadar dan tak sadar. Dengan pusat kalbu yang terdalam, yang dalam keadaan jernih berkilauan, seorang salik mampu melihat Allah Yang Maha Ghaib, jauh tersembunyi dalam pandangan mata biasa. Dalam Serat Wedhatama karya Mangkunegara IV dikenal adanya istilah sembah raga, sembah cipta, sembah jiwa dan sembah rasa yang merupakan derivasi idiom tasawuf Islam syariat, tarikat, hakikat, makrifat.

Pada dasarnya keempat sembah tersebut dapat dikatakan sebagai bentuk akulturasi kebudayaan. Ajaran tasawuf Islam mengalami transformasi dalam budaya Jawa. 
Mangkunegara IV sebagai pujangga berusaha untuk memasukkan unsur-unsur Islam lewat Serat Wedhatama. Dengan menggunakan metrum tembang macapat, maka ajaran sufisme Jawa yang mengandung nilai keislaman itu dapat diterima oleh masyarakat secara mengakar dan meluas. Syair-syair ajaran Serat Wedhatama merupakan bahan refleksi spiritual.

Berdasarkan latar belakang sebagaimana deskripsi di atas, maka pembahasan ini mempunyai tujuan untuk mengungkapkan nilai-nilai theologis dalam Serat Wedhatama. Pembahasan terhadap Serat Wedhatama meliputi dasar theologis Jawa, jalan menuju sufisme, subtansi ajaran kebatinan, dan mencapai puncak mistik. Dengan pembahasan secara theologis ini diharapkan akan dapat diperoleh pemahaman tentang sistem nilai-nilai spiritual Jawa yang merupakan sumber kearifan lokal.

\section{B. DASAR THEOLOGIS JAWA}

Pemikiran etik religius Mangkunegara IV pada dasarnya sesuai dengan konsep musyahadah Al Qusyairi yakni melihat Allah dengan mata hati, kelihatan kesesuaian antara keduanya. Nilai theologis dalam Wedhatama dijelaskan dengan idiom sinimpen telenging kalbu yakni alat untuk melihat Tuhan setelah terlebih dahulu dibukakan tabir yang menutupiNya. Pemikiran theologis Jawa yang menempati strata paling dasar adalah tatacara panembah kepada Tuhan Yang Maha Kuasa.

Secara teoritis konsep sembah atau panembah dikemukakan Mangkunegara IV dalam Serat Wedhatama (Ardani, 1995: 96). Konsep ini dikaitkan dengan kemuliaan budi luhur dan kehinaan budi jahat. Sembah dan budi luhur adalah dua hal yang menyatu, senafas dan saling berkait, dalam rangka mendekatkan diri kepada Tuhan sedekat-dekatnya.

Sembah raga ialah menyembah Tuhan dengan mengutamakan gerak laku badaniah, atau amal perbuatan yang bersifat lahiriah. Cara bersucinya sama dengan sembahyang biasa, yaitu dengan mempergunakan air (wudlu). Sembah yang demikian biasa dikerjakan lima kali sehari semalam, dengan mengindahkan pedoman secara tepat tekun dan terus-menerus, seperti bait berikut:
Sembah raga puniku
pakartining wong amagang laku
sesucine asarana saking warih
kang wus lumrah limang wektu
wantu wataking wawaton.

Terjemahan :

Sembah raga adalah

Perbuatana orang yang sedang melakukan

Bersuci dengan air bening

Biasa disebut lima waktu

Saat yang sudah ditentukan

Perjalanan hidup yang panjang ditamsilkan sebagai orang yang magang laku atau penempuh perjalanan hidup kerohanian, sebagai orang yang menjalani tahap awal kehidupan bertapa. Sembah ini didahului dengan bersuci yang menggunakan air. Sembah raga ditunaikan sehari semalam lima kali. Atau dengan kata lain bahwa untuk menunaikan sembah ini telah ditetapkan waktu-waktunya, lima kali dalam tiap-tiap sehari semalam. Sembah lima waktu merupakan shalat fardlu yang wajib ditunaikan terus menerus tiada henti seumur hidup, dengan keharusan memenuhi segala ketentuan syarat dan rukun yang wajib dipedomani. Watak suatu pedoman harus dipedomani (Hazim Amir, 1994: 71). Tanpa mempedomani syarat dan rukun, maka sembah itu tidak sah.

Shalat lima waktu merupakan shalat fardlu yang wajib ditunaikan setiap muslim dengan memenuhi segala syarat dan rukunnya, wantu wataking wawaton. Sembah raga yang demikian ini wajib ditunaikan terus-menerus tiada henti seumur hidup. Dengan keharusan memenuhi segala ketentuan syarat dan rukun yang wajib dipedomani. Watak suatu waton harus dipedomani. Tanpa mempedomani syarat dan rukun, maka sembah itu tidak sah. Sembah raga tersebut, meskipun lebih menekankan gerak laku badaniah, namun bukan berarti mengabaikan aspek rohaniah, sebab orang yang magang laku selain ia menghadirkan seperang- 
kat fisiknya, ia juga menghadirkan seperangkat aspek spiritualnya sehingga ia meningkat ke tahap kerohanian yang lebih tinggi.

\section{JALAN MENUJU SUFISME}

Bagi orang Jawa jalan menuju kehidupan sufisme dapat dilalui dengan cara Sembah Cipta. Sembah cipta kadang-kadang disebut kadang-kadang disebut juga dengan istilah sembah kalbu, seperti terungkap pada bait tembang gambuh sebagai berikut:

Samengko sembah kalbu
yen lumintu uga dadi laku
laku agung kang kagungan narapati
patitis teteking kawruh
meruhi marang kang momong

Terjemahan :

Sekarang sembah kalbu

Jika dibiasakan menjadi laku

Laku agung milik sang raja

Tepat sebagai sumber ilmu

Mengetahui kepada yang mengasuh

Apabila cipta mengandung arti gagasan, angan-angan, harapan atau keinginan yang tersimpan dalam hati, kalbu berarti hati, maka sembah cipta di sini mengandung arti sembah kalbu atau sembah hati, bukan sembah gagasan atau angan-angan. Apabila sembah raga menekankan penggunaan air untuk membasuh segala kotoran dan najis lahiriah, maka sembah kalbu menekankan pengekangan hawa nafsu yang dapat mengakibatkan terjadinya berbagai pelanggaran dan dosa (sucine tanpa banyu, amung nyunyuda hardaning kalbu).

Bersuci itu dalam tuntunan Islam ada empat tingkat. Pertama, membersihkan hadats dan najis yang bersifat lahiriah. Kedua, membersihkan anggota badan dari berbagai pelanggaran dan dosa. Ketiga, membersihkan hati dari akhlak yang tercela dan budi pekerti yang hina. Keempat, membersihkan hati nurani dari apa yang selain Allah. Cara bersuci yang keempat inilah thaharah pada Nabi dan Shiddiqin. Jika thaharah yang pertama dan kedua menurut Al-Ghazali masih menekankan bentuk lahiriah berupa hadats dan najis yang melekat di badan yang berupa pelanggaran dan dosa yang dilakukan oleh anggota tubuh. Cara membersihkannya dibasuh dengan air. Sedangkan kotoran yang kedua dibersihkan dan dibasuh tanpa air yaitu dengan menahan dan menjauhkan diri dari pelanggaran dan dosa. Thaharah yang ketiga dan keempat juga tanpa menggunakan air. Tetapi dengan membersihkan hati dari budi jahat dan mengosongkan hati dari apa saja yang selain Allah.

Istilah pandangan hidup Jawa mempergunakan pengertian yang longgar, jadi istilah ini dapat saja diganti dengan istilahistilah lain yang memiliki arti yang kurang lebih sama, seperti Filsafat Jawa, Filsafah Kejawen atau istilah lain lagi (Ciptoprawiro, 1986: 18). Tetapi pandangan hidup Jawa, ini tidaklah identik dengan Aliran Kepercayaan Terhadap Tuhan Yang Maha Esa atau Islam Abangan atau Mistik Jawa dan lebih-lebih dengan ilmu-ilmu klenik. Sementara itu beberapa istilah lain seperti Agama Jawa (Koentjaraningrat, 1984: 204), The Religion of Java (Clifford Geertz, 1991: 29) dan lain-lain, itu tidak identik dengan Pandangan Hidup Jawa sekalipun tampak adanya beberapa segi persamaan. Arti ini lebih serasi dengan makna yang terkandung dalam kata muslim dan mutaqqi yang berarti menyerah, tunduk menjaga diri dari hukuman Tuhan, dengan mematuhi perintah dan menjauhi larangan-larangan-Nya.

Dengan perkataan lain, manusia diciptakan Tuhan sebenarnya ialah untuk berbuat baik dan menjauhi kejahatan, karena Tuhan hanya menyuruh apa yang baik dan melarang yang jahat (Ardani, 1995: 23). Apabila cipta mengandung arti gagasan, anganangan, harapan atau keinginan yang tersimpan dalam hati, sedangkan kalbu berarti hati, maka sembah cipta di sini mengandung arti sembah kalbu atau sembah hati, bukan sembah gagasan atau angan-angan (Poerwadarminta, 1939: 286). Secara keseluruhan makna Ingkang Akarya Jagat adalah yang membuat dunia. dunia raya seluruhnya ini diyakini oleh orang Jawa bahwa ada yang menciptakan. Ilmu sangkan paraning dumadi menunjukkan asal- 
usul kehidupan dan tujuannya. Dunia pasti ada awalnya dan ada akhirnya. Namun Sang Pencipta tanpa awal akhir, karena awal akhir hanya menguasai makhluk.

Ingkang Murbeng Gesang adalah yang menguasai kehidupan. Kepasrahan kepada yang menguasai hidup ini membuat orang Jawa tidak risau terhadap segala jenis perubahan sosial yang sedang terjadi. Dalam logika sederhana, penguasa pesti memiliki kasih sayang terhadap yang dikuasai atau makhluknya. Duka nestapa selalu dipahami sebagai ganjaran dari Ingkang Murbeng Gesang.

Hyang Suksma Adiluwih artinya adalah Tuhan Yang Maha Lebih. Segala yang ada di dunia ini selalu di bawah keberadaan Tuhan. Dengan mengakui Yang Maha Lebih ini, orang Jawa menghindari sikap sombong. Sebaik-baik makhluk dan sehebat-hebat ciptaan masih amat jauh dibanding dengan kekuatan yang menciptakan. Singkat kata antara makhluk dengan yang menciptakan memang tidak bisa dibandingkan.

Sembah cipta atau sembah kalbu ialah menyembah Tuhan dengan lebih mengutamakan peranan kalbu. Sembah ini, seperti halnya sembah raga, apabila dilakukan terus menerus secara teratur, juga dapat menjadi jalan yang mengantarkan kepada tujuan, bahkan merupakan jalan raya 'sang raja kerohanian' yang tengah menjalani tarikat dan suluk dalam perjalanan kerohaniannya (yen lumintu uga dadi laku, laku agung kang kagungan narapati) (Ardani, 1995: 142). Sekalipun sembah kalbu lebih mengutamakan kesucian batin, namun bukan berarti meniadakan peranan kebersihan dan kesucian lahir. Oleh karena itu thaharah pada sembah raga perlu dihayati dan diberi makna batini dalam sembah kalbu, sehingga taharah tersebut mengandung makna lahir dan batin secara terpadu (Ardani, 1995: 156). Sekalipun telah cukup jelas petunjuk-petunjuk pelaksanaan sembah kalbu seperti disebut di muka, namun seorang salik perlu memperhatikan dengan seksama apa yang menjadi penghalang yang bakal menggagalkan perjalanan menuju Allah.
Penyebab kegagalan menurut Mangkunegara IV, apabila ia selalu memperturutkan kemauan pribadinya, mengharap apa yang diinginkan terpenuhi, padahal begitu banyak keinginan itu yang biasanya karena dorongan hawa nafsu, lalu menyebabkan lalai berdzikir kepada Allah. Jika hal yang demikian diperturutkan, gagallah apa yang dicita-citakan. Maka hendaklah ia sadar dan waspada apa yang menyebabkan gagalnya perjalanan mencapai tujuan.

\section{SUBSTANSI AJARAN KEBATINAN}

Pada perjalanan spiritual tertentu diharapkan seseorang dapat memahami substansi ajaran kebatinan melalui sembah jiwa. Sembah jiwa adalah sembah kepada Hyang Suksma dengan mengutamakan peran jiwa. Jika sembah cipta mengutamakan peran kalbu, maka sembah jiwa lebih halus dan mendalam dengan menggunakan jiwa atau $\mathrm{Al}$ ruh. Sembah ini hendaklah diresapi secara menyeluruh tanpa henti setiap hari, dilaksanakan dengan tekun secara terus menerus seperti tampak pada bait berikut:

Samengko kang tinutur
sembah katri kang sayekti katur
mring Hyang Suksma suksmanen saari ari
arahen dipun kacakup
sembahingjiwa sutèngong.

Terjemahan :

Sekarang yang dituturkan

Sembah yang ketiga

Kepada Tuhan yang dihayati sehari-hari

Dengan tujuan meliputi segalanya

Sembah jiwa anakku.

Menurut pandangan ilmu mistik kebatinan orang jawa, kehidupan manusia merupakan bagian dari jagad raya secara keseluruhan, dan hanya merupakan bagian yang sangat kecil dari kehidupan jagad raya yang abadi, di mana manusia itu seakan-akan hanya berhenti sebentar untuk minum. Menurut Serat Jamus Kalimasada, ajaran kebatinan Jawa adalah sufi Jawa yang utuh. Ia mengajarkan manunggaling kawula Gusti atau 
sangkan paraning dumadi. Menurut ajaran Jawa, perihal manunggaling kawula Gusti itu dapat diibaratkan sebagai rangka umanjing curiga, tempat keris yang meresap masuk ke dalam kerisnya (Haryanto, 1988: 76).

Wisesa bertindak sebagai wakil Allah, yaitu ingsun (aku, saya), yang membikin rumah besar, yang merupakan dinding (tirai) yaitu badan atau tubuh kita (yaitu yang merupakan realisasi kehadirannya ingsun). Yang bersujud adalah mahkluk, sedang yang disujudi adalah Khalik, (Allah, Tuhan). Hal ini sebenarnya hanya terdindingi oleh sifat. Maksudnya, hudip mandiri itu sebenarnya telah berkumpul menjadi satu antara mahkluk dan Khaliknya.

Selanjutnya menurut ajaran Jawa, yang bertindak mencari sandang pangan kita seharihari adalah Sadherek gangsal kalima pancer. Adapun jiwa kita diibaratkan oleh ajaran Jawa sebagai mandor. Seorang mandor harus mengawasi kuli-kulinya. Atau lebih singkatnya dikatakan sebagai berikut: Gajah Sena saudara Wrekodara yang berwujud gajah. Singkatnya saudara yang berjumlah lima itu mengibaratkan ilmu ke-Tuhan-an. Hal ini perlu dicapai (yaitu tiga saudara, empat dan lima pokoknya). Adapun yang bekerja mencari sandang pangan setiap hari itu adalah saudara kita berlima itu. Adapun jiwa (sukma) kita bertindak sebagai mandor. Itulah sebabnya mandor harus berpegang teguh pada kekuasaan yang berada ditangannya untuk mengatur anak buahnya, agar semuanya selamat. Sebaliknya apabila anak buahnya tadi betindak salah dan tindakan tersebut dibiarkan saja, maka lama kelamaan mereka kian berbuat seenaknya. Hal ini akan mengakibatkan penderitaan.

Pengandaian jiwa sebagai mandhor dan sedulur papat kalima pancer sebagai kulikuli tersebut di atas adalah sangat menarik. Kata-kata ini erat hubungannya dengan kerja paksa/kerja rodi di hutan-hutan jati di daerah Blora dan sekitarnya. Pekerja rodi terdiri dari mandor dan kuli. Mandor berfungsi sebagai pengawas, sedangkan kuli berfungsi sebagai pekerja. Pemakaian kata yang sederhana tersebut oleh ajaran Jawa dikandung maksud agar ajarannya dapat dimengerti oleh siswa- siswanya yang umumnya adalah orang desa yang terkena kerja paksa.

Tugas manusia di dunia adalah sebagai utusan Tuhan. Jadi apa yang dialami oleh manusia di dunia adalah kehendak Tuhan. Oleh karena itu sedih dan gembira, sehat dan sakit, bahagia dan sedih, harus diterima sebagai hal yang wajar. Hal tersebut bisa dilihat pada ajarannya yang berbunyi : Menurut perjanjian, manusia adalah pesuruh Tuhan di dunia untuk menambah keindahan jagad raya. Dalam hubungan ini masyarakat harus menyadari bahwa mereka hanyalah sekedar melaksanakan perintah. Oleh karena itu apabila manusia mengalami kebahagiaan dan kecelakaan, sedih dan gembira, sehat dan sakit, semuanya harus diterima tanpa keluhan, sebab manusia terikat dengan perjanjiannya. Yang terpenting adalah manusia hidup di dunia ini harus mematuhi hukum Tuhan, yaitu memahami pada asalusulnya masing-masing. Arah tujuannya agar dapat berbuat baik dengan niat yang sungguhsungguh, sehingga tidak ragu-ragu lagi.

Pelaksanaan sembah jiwa ialah dengan berniat teguh dalam hati untuk mengemaskan segenap aspek jiwa, lalu diikatnya kuat-kuat untuk diarahkan kepada tujuan yang hendak dicapai tanpa melepaskan apa yang telah dipegang pada saat itu. Dengan demikian triloka (jagad raya) tergulung menjadi satu. Begitu pula jagad besar dan jagad kecil digulungkan disatupadukan. Di situlah tampak dunia yang bersinar gemerlapan. Maka untuk menghadapi keadaan yang menggumkan itu, hendaklah perasaan hati dipertebal dan diperteguh jangan terpengaruh apa yang terjadi. Dalam rangkaian ajaran sembah Mangkunegara IV yang telah disebut terdahulu, maka sembah jiwa ini menempati kedudukan yang amat penting. Ia disebut pepuntoning laku (pokok tujuan atau akhir perjalanan suluk). Inilah akhir perjalanan hidup batiniah. Cara bersucinya tidak seperti pada sembah raga dengan air wudlu atau mandi, tidak pula seperti pada sembah kalbu dengan menundukkan hawa nafsu, tetapi dengan awas emut (selalu waspada dan ingat/dzikir) kepada keadaan dunia baka (langgeng), dunia Ilahi. 
Berbeda dengan sembah raga dan sembah kalbu, ditinjau dari segi perjalanan suluk, sembah ini adalah tingkat akhir perjalanan tersebut, sedangkan sembah yang pertama adalah tingkat permulaan (wong amagang laku) dan sembah yang kedua adalah tingkat lanjutan. Dan ditinjau dari segi tata cara pelaksanaannya, sembah yang pertama menekankan kesucian jasmaniah dengan menggunakan alat air dan sembah yang kedua menekankan kesucian kalbu dari pengaruh jahat hawa nafsu lalu membuangnya dan menukarnya dengan sifat utama, sedangkan sembah ketiga menekankan pengisian seluruh aspek jiwa dengan dzikir kepada Allah.

\section{E. MENCAPAI PUNCAK MISTIK}

Dalam struktur kepercayaan orang Jawa, mencapai puncak mistik dapat dicapai dengan sembah rasa. Sembah rasa ini berlainan dengan sembah-sembah yang sebelumnya. Ia didasarkan kepada rasa cemas. Sembah yang keempat ini ialah sembah yang dihayati dengan merasakan intisari kehidupan makhluk semesta alam, demikian menurut Mangkunegara IV. Beliau adalah sufi Jawa sekaligus raja yang adil, ber budi bawa leksana yang telah mencapai sembahrasa.

Maksud ungkapan ber budi adalah sikap seorang yang murah hati, suka memberi ganjaran, berdana ria dan selalu memikirkan kesejahteraan bawahan dan rakyatnya. Seseorang memiliki kesempatan yang berlimpah ruah untuk mengumpulkan kemakmuran, kenikmatan dan kehormatan tanpa banyak harus bersusah payah. Namun bila hasilnya tidak disebarkan secara merata dan adil maka kenikmatan itu akan menjelma menjadi senjata makan tuan. Bahkan suatu saat akan menjatuhkan diri dan martabatnya. Ungkapan ber budi maknanya asring paring dana. Tindak kongkritnya yaitu anggeganjar saben dina yang bermakna seorang pemimpin yang pemurah, kreatif, inovatif serta memiliki kepribadian agung. Arti ungkapan bawa leksana adalah menepati dan menetapi katakata. Sabda brahmana raja sepisan kudu dadi tan kena wola-wali, mengandung makna bahwa perkataan ulama dan umara itu harus bisa dipegang. Oleh karena itu sebelum diucapkan harus dipikirkan masak-masak.

Raja dan brahmana merupakan figur panutan yang diikuti oleh banyak orang. Idiom esuk dhele sore tempe hanya patut diucapkan oleh pedagang di pasar yang hanya mengejar laba tak memikirkan dampak kata-katanya. Sangat berbahaya bila pemuka masyarakat cepat-cepat berubah ucapannya hanya untuk menuruti selera sesaat (Poerbatjaraka, 1964: 17). Orang yang mencla-mencle akan menyusahkan. Lire kang bawa leksana anetepi pangandika adalah suatu ungkapan yang penuh dengan prinsip luhur yang perlu dipraktikkan para pemimpin.

Jika sembah kalbu mengandung arti menyembah Tuhan dengan alat batin kalbu atau hati seperti disebutkan sebelumnya, sembah jiwa berarti menyembah Tuhan dengan alat batin jiwa atau ruh, maka sembah rasa berarti menyembah Tuhan dengan menggunakan alat batin inti ruh. Alat batin yang belakangan ini adalah alat batin yang paling dalam dan paling halus yang menurut Mangkunegara IV disebut telenging kalbu (lubuk hati yang paling dalam) atau disebut wosing jiwangga (inti ruh yang paling halus).

Dengan demikian menurut Mangkunegara IV, dalam diri manusia terdapat tiga buah alat batin yaitu, kalbu, jiwa/ruh dan inti jiwa/inti ruh (telengking kalbu atau wosing jiwangga) yang memperlihatkan susunan urutan kedalaman dan kehalusannya. Pelaksanaan sembah rasa itu tidak lagi memerlukan petunjuk dan bimbingan guru seperti ketiga sembah sebelumnya, tetapi harus dilakukan salik sendiri dengan kekuatan batinnya, seperti diungkapkan Mangkunegara IV dalam bait berikut:

Semongko ingsun tutur
gantya sembah lingkang kaping catur
sembah rasa karasa wosing dumadi
dadi wus tanpa tuduh
mung kalawan kasing batos.

Terjemahan :

Sekarang saya bertutur 
Ganti sembah yang keempat

Sembah rasa yang menjadi inti hidup

Jadi sudah tanpa arahan

Hanya dengan kekuatan batin

Apabila sembah jiwa dipandang sebagai sembah pada proses pencapaian tujuan akhir perjalanan suluk, pepuntoning laku, maka sembah rasa adalah sembah yang dilakukan bukan dalam perjalanan suluk itu, melainkan sembah yang dilakukan di tempat tujuan akhir suluk. Dengan kata lain, seorang salik telah tiba di tempat yang dituju. Di sinilah akhir perjalanan suluknya. Untuk sampai di sini, seorang salik masih tetap dibimbing gurunya seperti telah disebut di muka. Setelah ia diantarkan sampai selamat oleh gurunya untuk memasuki pintu gerbang, tempat sembah yang keempat, maka selanjutnya ia harus mandiri melakukan sembah rasa (Darmanto, 1997: 28).

Pada tingkatan ini, seorang salik dapat melaksanakan sendiri sembah rasa sesuai petunjuk-petunjuk gurunya. Pada tingkat ini ia dipandang telah memiliki kematangan rohani. Oleh karena itu, ia dipandang telah cukup ahli dalam melakukan sembah dengan mempergunakan aspek-aspek batiniahnya sendiri. Ciri orang yang sudah mencapai tataran sembah rasa ini adalah anteng, meneng, jatmika, sembada, dan wiratama. Anteng bermakna tenang, halus, indah tapi berbobot. Ada pepatah: air beriak tanda tak dalam, air tenang menghanyutkan, yaitu larangan untuk meremehkan hal-hal yang kelihatan remeh yang tak berdaya.

Sikap anteng akan menimbulkan kewibawaan dan mendatangkan rasa hormat dari pihak lain. Dalam proses belajar mengajar, sikap anteng itu sangat diperlukan. Guru akan merasa dihargai jika siswanya bersikap anteng. Dengan sikap anteng berarti siswa memperhatikan dan memahami ajaran gurunya. Suasana gaduh akan membuat pelajaran tidak bisa dipahami dan emosi mudah terbakar.

Dalam forum resmi sikap anteng diperlukan demi kelancaran hal yang sedang dibicarakan. Keputusan yang dihasilkan oleh forum yang anteng pesertanya maka hasilnya akan lebih jernih. Dalam kehidupan sehari-hari pribadi yang anteng bisanya mampu berpikir lebih jernih untuk memecahkan berbagai persoalan (Haryanto, 1988: 63). Meneng artinya diam. Namun diam di sini bukan dalam arti tanpa sikap dan tidak tahu persoalan. Seseorang harus diam di kala tertentu agar suasana tidak menjadi keruh. Suasana yang panas akibat dari ucapan yang bermacammacam menambah potensi konflik menajam dan perselisihan meruncing. Pilihan untuk diam merupakan sikap terbaik dan bijaksana. Di sini bisa dikatakan: diam adalah emas. Apabila konflik memuncak dan ujung kompromi tak diketemukan, biasanya mereka akan berpaling kepada pihak yang tidak banyak bicara. Dan barulah pihak ini memberikan solusi yang jernih dan efektif. Tindakan diam juga bisa digunakan untuk menghadapi orang keras. Orang keras kalau dihadapi secara frontal akan bertambah beringas. Dengan diam, lamakelamaan ia akan sadar diri.

\section{F. PENUTUP}

Berdasarkan uraian di atas, maka nilai theologis dalam Serat Wedhatama dikenal adanya istilah sembah raga, sembah cipta, sembah jiwa dan sembah rasa. Syariat atau sembah raga adalah tahap yang paling mula, yaitu manusia harus menghormati dan hidup sesuai dengan rukun agama menjalankan kewajiban dengan sungguh-sungguh; menghargai dan menghormati orang tua, guru, pemimpin dan raja; mematuhi aturan sosial, dan menjaga keselarasannya; serta mengakui tatanan kosmos (Subagyo, 1976: 82). Manusia sadar bahwa dengan emnghormati orang tua, guru, dan raja berarti menghormati Tuhan serta mengakui ada-Nya.

Tarikat atau sembah cipta adalah tahap yang lebih maju setapak. Dalam tahap ini segala tingkah laku pada tahap yang pertama lebih ditingkatkan dan diperdalam, yaitu dengan bertobat dan menyesali segala dosa; menjauhi larangan Tuhan dan menjalankan perintah-Nya; melakukan puasa yang diwajibkan; mengurangi makan, minum, dan tidur (Hadiwijono, 1983: 97). Kecuali sikap demikian itu disebutkan pula bahwa orang yang telah mencapai tahap tarikat di antaranya ia akan 
sabar dan tenang dalam segala tindakan; meninggalkan segala yang hal di dalamnya terdapat keraguan; dan tawakal atau berserah diri kepada keputusan serta ketetapan Tuhan.

Hakikat atau sembah jiwa adalah tahap yang sempurna. Pencapaian tahap ini diperoleh dengan mengenal Tuhan melalui pengetahuan yang sempurna dengan cara berdoa terusmenerus; menyebut nama Tuhan dan mencintai-Nya; mengenali Tuhan dan dirinya sendiri; acuh terhadap kesenangan dan kesusahan, karena senang-susah, kaya-miskin, nyaman-sakit, semuanya itu merupakan wujud Tuhan, yang berarti berasal dari Tuhan. Segala sesuatu milik Tuhan dan akan kembali kepadaNya, manusia hanya mengaku saja (Zoetmulder, 1991: 138). Tahap ini disebut tahap keadaan mati dalam hidup, dan hidup dalam mati; maknanya yang mati di sini adalah nafsunya.

Makrifat atau sembah rasa adalah tahap terakhir atau tertinggi, yaitu tahap manusia telah menyatukan dirinya dengan Ilahi, tahap manusia telah mencapai kemanunggalan dengan Tuhan. Dalam tahap ini, jiwa manusia terpadu dengan jiwa semesta, tindakan manusia semata-mata menjadi laku (Mulyono, 1978: 54). Pada tahap ini, manusia tidak akan diombang-ambingkan oleh sukaduka dunia, berseri bagaikan bulan purnama menyinari bumi, membuat dunia indah dan damai; menjadi wakil Tuhan di dunia dan menjalankan kewajiban-kewajiban-Nya. Singkat kata, mereka sudah meninggalkan dunia sebelum meninggal dunia. Pada akhirnya dia akan memperoleh derajat khusnul khotimah.

\section{DAFTAR PUSTAKA}

Ardhani. 1995. Pemikiran KGPA Mangkunegara IV. Semarang : Dahara Prize.

Ciptoprawiro, 1986. Filsafat Jawa. Jakarta : Gramedia.

Clifford Geertz, 1991. Santri Abangan Priyayi. Jakarta : LP3ES.

Darmanto, 1997. Ajaran Hidup Serat Wedhatama. Surakarta: Cendrawasih

Hadiwijono, 1983. Kepercayaan Orang Jawa. Yogyakarta: Kanisius.

Haryanto, 1988, Pratiwimba Adiluhung Sejarah dan Perkembangan Wayang, Jakarta: Djambatan.

Hazim Amir, 1994. Nilai-nilai Etis dalam Pewayangan, Jakarta : Sinar Harapan.

Kamajaya, 1992. Karangan Pilihan KGPAA. Mangkunegara IV. Yogyakarta: Yayasan Centhini.

Koentjaraningrat, 1984. Kebudayaan Jawa. Jakarta : Balai Pustaka.

Magnis Suseno, 1993. Etika Jawa. Jakarta : Gramedia.

Mulyono, 1978. Simbolisme, Mistikisme dan Filsafat dalam Pewayangan. Jakarta : Gunung Agung.

Poerbatjaraka, 1964. Kapustakan Jawi, Jakarta : Djambatan.

Poerwadarminta, 1939. Bausastra Jawa, Groningen, Batavia : JB Wolter's Uitgevers' Maatschappij NV.

Subagyo, 1973. Kebatinan Jawa. Yogyakarta : Kanisius.

Zoetmulder, 1991. Manunggaling Kawula Gusti. Jakarta: Gramedia. 